\title{
Contribuições do Design da informação para a visibilidade de conteúdos que perpassem a temática LGBT, diversidade de gênero e sexualidade convergidos em Repositórios Digitais. Contributions of Information Design to the visibility of contents that cross the LGBT theme, gender diversity and sexuality converged in Digital Repositories.
}

\author{
Maria José Vicentini Jorente \& Simão Marcos Apocalypse
}

Design da Informação, Repositórios institucionais, LGBT, Diversidade de Gênero e Sexualidade.

\begin{abstract}
O desenvolvimento das Tecnologias de Informação e Comunicação (TIC), pós Segunda Guerra Mundial trouxe consideráveis mudanças referentes à produção e acesso à informação. Esse desenvolvimento possibilitou a criação de diversos recursos, como Repositórios Digitais (RD). A problemática apresentada no presente trabalho consiste na seguinte questão: de que maneira o Design dos recursos utilizados no repositório digital da Unesp permite visualizar as produções científicas relacionadas à temáticas LGBT, diversidade de gênero e sexualidade? O estudo tem como objetivo identificar as contribuições do Design da Informação (DI) para a visibilidade de pesquisas que versem sobre temáticas pouco disseminadas convergidas em RD, bem como contribuir para o melhoramento no compartilhamento de informações convergidas em repositórios, à toda sociedade de forma eficiente e eficaz. Justifica-se pela necessidade do compartilhamento de conteúdos pouco disseminados. A metodologia utilizada é de caráter teórico exploratório, que consiste em uma revisão de literatura referente às temáticas abordadas e um estudo exploratório do Repositório Institucional da Unesp. A característica dinâmica do DI torna possível identificar os princípios adequados a sua aplicação em repositórios, configurando um campo de estudo para a construção eficiente e eficaz desses espaços, cuja principal função é o compartilhamento de conhecimentos e contribuir para a eliminação da ignorância sobre a diversidade de gênero e sexualidade.
\end{abstract}

\section{Information Design, Institutional Repositories, LGBT, Gender Diversity and Sexuality.}

The development of Information and Communication Technologies (ICT), after World War II, has brought about considerable changes regarding the production and access to information. This development allowed the creation of several resources such as Digital Repositories (DR). The problem presented in the present work is the following question: in what way does the Design of the resources used in the Unesp repository allow visualizing the scientific productions related to LGBT themes, gender diversity and sexuality? The objective of this study is to identify the contributions of Information Design (ID) to the visibility of researches that deal with little disseminated themes converged in DR, as well as to contribute to the improvement in the sharing of information converged in repositories throughout society in an efficient and effective manner. It is justified by the need to share slight disseminated content. The methodology used is of an exploratory theoretical nature, which consists of a review of the literature on the topics addressed and an exploratory study of the Institutional Repository of Unesp. The dynamic characteristic of the ID makes it possible to identify the appropriate principles for its application in repositories, configuring a field of study for the efficient and effective construction of these place, whose main function is the sharing of knowledge and contribute to the elimination of ignorance about the diversity of gender and sexuality.

\section{Introdução}

O desenvolvimento das Tecnologias de Informação e Comunicação (TIC), pós Segunda Guerra Mundial trouxe consideráveis mudanças referentes à produção e acesso à informação. Esse desenvolvimento possibilitou a criação de diversos recursos como Repositórios Digitais (RD) que possuem como função armazenar informações de determinada instituição de forma segura e permanente, disponibilizar e também conferir visibilidade a esse material em meio à sociedade (Leite et al, 2012).

\author{
Anais do 9 CIDI e 9 CONGIC \\ Luciane Maria Fadel, Carla Spinillo, Anderson Horta, \\ Cristina Portugal (orgs.) \\ Sociedade Brasileira de Design da Informação - SBDI \\ Belo Horizonte | Brasil | 2019 \\ ISBN 978-85-212-1728-2
}

Proceedings of the 9th CIDI and 9th CONGIC

Luciane Maria Fadel, Carla Spinillo, Anderson Horta,

Cristina Portugal (orgs.)

Sociedade Brasileira de Design da Informação - SBDI

Belo Horizonte | Brazil | 2019

ISBN 978-85-212-1728-2 
O presente artigo corresponde ao estudo do Repositório Institucional Digital da Universidade Estadual Paulista (UNESP) buscando compreender a forma como as produções científicas relacionadas a temáticas $\mathrm{LGBT}^{1}$ como diversidade de gênero e sexualidade estão dispostas neste ambiente e como o Design da Informação (DI) pode contribuir para a visibilidade desses conteúdos.

Segundo Planella Ribera (2017) as produções científicas acerca dessas temáticas, embora abordadas no âmbito acadêmico, ainda possuem grande nebulosidade perante a sociedade e necessitam ser compartilhadas de modo eficiente e eficaz. Neste contexto, são necessárias investigações acerca de recursos que possibilitem melhor encontrabilidade e visibilidade de conteúdos convergidos em Repositórios. O DI tem como característica possibilitar a melhoria dos trânsitos de informação, com intuito de auxiliar no processo apreensão da informação disponível em um determinado ambiente (Jorente, 2015).

Ao considerar os recursos da Web, a problemática apresentada no presente trabalho consiste na seguinte questão: de que maneira o Design dos recursos utilizados no repositório da UNESP permite visualizar as produções científicas relacionadas à temática LGBT, diversidade de gênero e sexualidade?

O estudo tem como objetivo identificar as contribuições do DI para a visibilidade de pesquisas que versem temáticas pouco disseminadas convergidas em $\mathrm{RD}$, bem como contribuir para o melhoramento no compartilhamento de informações convergidas em repositórios a toda sociedade. Assim, justifica-se pela necessidade de que conteúdos que possuem carências informacionais sejam compartilhadas de modo eficiente e eficaz.

Para a sua realização a metodologia utilizada é de caráter teórico exploratório, que consiste em revisão de literatura referente às temáticas abordadas e um estudo exploratório do Repositório Institucional da UNESP. Preliminarmente efetivou-se um levantamento bibliográfico referente às temáticas LGBT, diversidade de gênero e sexualidade, a fim de compreender a importância de sua abordagem nos ambientes universitários e como o desenvolvimento das TIC e o surgimento dos repositórios institucionais em convergência com o DI podem contribuir para que as produções deste segmento adquiram maior visibilidade.

Posteriormente foi realizada uma análise da interface do repositório considerando princípios de Design, identificando suas características e se as mesmas possibilitam o compartilhamento do conteúdo informacional tratado pela pesquisa e possíveis melhorias.

Considerando a maleabilidade dos princípios efetivou-se uma seleção de princípios e diretrizes a serem consideradas pré-apresentação da informação e princípios cabíveis de aplicação ao ambiente já construído.

Para tanto, foram resgatadas imagens da interface do Repositório Institucional da UNESP, simulando o percurso realizado por um indivíduo comum que venha realizar buscas no ambiente. Deste modo, as imagens selecionadas correspondem à página inicial do repositório completa, a primeira página de resultados de buscas mediante da busca pelo termo LGBT, e a página final, que se encontra o documento.

\section{Sujeitos LGBT}

A abordagem referente ao sexo, sexualidade, gênero e corpo, ao longo do desenvolvimento das civilizações humanas, foi concebida de diferentes modos. Na atualidade observa-se um

\footnotetext{
${ }^{1}$ Em um resgate histórico do movimento LGBT, identifica-se que o uso de siglas como forma de representar os diferentes segmentos que compunham o movimento, passou e na atualidade ainda passam por diversas modificações. Para a efetivação desta pesquisa, a sigla escolhida é a LGBT (lésbicas, gays, bissexuais, transexuais e travestis) contudo cabe ressaltar que a mesma não é estática e embora seja a mais usual na atualidade, não contempla todos os indivíduos que destoam da norma heterossexual (Ribeiro Júnior, 2016)
} 
Jorente, M. J. V. \& Apocalypse, S. M. | Contribuições do Design da informação para a visibilidade de conteúdos que perpassem a temática LGBT, diversidade de gênero e sexualidade convergidos em

movimento de estudos que buscam compreender os fatores históricos-sociais das diversas concepções que perpassam tais assuntos nos diferentes nichos sociais em diferentes épocas.

O filósofo Michel Foucault (1926-1984) foi um dos primeiros teóricos a abordar a sexualidade em uma perspectiva histórica- social. Assim, o teórico destaca o valor normativo social a qual a sexualidade foi atribuída: sexualidade como um dispositivo de saber e poder, meio pelo qual se possibilita criar hierarquias de poder a partir da normatização dos corpos. Deste modo, 'o dispositivo de sexualidade tem, como razão de ser, não o reproduzir, mas o proliferar, inovar, anexar, inventar, penetrar nos corpos de maneira cada vez mais detalhada e controlar as populações de modo cada vez mais global' (Foucault, 1988, p. 101).

A partir do reconhecimento da existência de sexualidades destoantes do considerado "normal" até o século fim XIX, os indivíduos até então renegados, iniciam um movimento em busca de reconhecimento e aceitação de seus corpos e comportamentos, neste contexto, despontam, diversos estudos, na busca de melhor compreender a existência de tais indivíduos.

Desse modo, após o trabalho propulsor de Michel Foucault, outros estudos com a finalidade de compreender as colocações referentes à construção normativa dos corpos e das concepções sobre gênero e sexualidade tomam espaço em meio aos saberes institucionalizados.

Butler (2014) aponta em seus estudos, novas concepções acerca das noções de gênero e sexualidade: os estudos propostos pela teoria Queer ${ }^{2}$. Estes buscam inicialmente romper com concepções que reduzem o gênero e a sexualidade como se fossem características indistintas, mas não somente, o autor propõe uma nova forma de se conceber as noções de gênero e sexualidade, pondo abaixo as noções binárias de gênero homem/mulher e sexualidade, heterossexual/homossexual, indo ainda mais além em suas colocações acerca da fluidez dessas construções.

Afim de melhor evidenciar a colocação dos sujeitos LGBT, a nível nacional, cabe resgatar estudos atuais, referente a essa parcela da população. Estudos oficiais são de extrema e imprescindível importância para que avanços sejam possibilitados referentes às lutas por igualdade.

Conforme dados apresentados pelo Relatório sobre violência homofóbica no Brasil: ano de 2012, foi contabilizado um total de 310 homicídios, dentre 511 violações contra sujeitos LGBT. Dados divulgados pelo Grupo Gay da Bahia (GGB), no ano de 2017, foram contabilizados um total de 445 homicídios motivados por LGBTfobia.

Verifica-se mediante aos dados apresentados pelos relatórios realizados em 2012, correlacionados com os dados apresentados pelo GGB em 2017, observa-se um grande aumento no número indivíduos mortos por LGBTfobia, visto que de acordo com os dados oficiais de 2012 foram registrados 310 homicídios e no ano de 2017 um total de 445, ou seja, um aumento de 135 mortes. Neste contexto, deve-se lembrar de que os dados apresentados não representam a totalidade das violências sofridas pelos indivíduos LGBT, mas sim apenas aos casos registrados.

É necessário, de fato, ressaltar a importância de estudos que versam as temáticas de diversidade de gênero e sexualidade e sujeitos LGBT, se construa nos ambientes universitários. Planella Ribera (2017) destaca a importância de que tais temáticas sejam abordadas no âmbito da academia.

Compreende-se a importância de pesquisas que perpassam as temáticas LGBT, diversidade de gênero e sexualidade, mediante ao panorama apresentado referente às condições de existência das minorias sexuais e de gênero na atualidade, ressaltando a

\footnotetext{
${ }^{2}$ A expressão queer, antes usada em discursos homofóbicos para taxar como esquisito ou estranho as diversas manifestações identitárias da homossexualidade, é tomada pelos integrantes do movimento gay que não se identificavam com as propostas do mesmo, como uma forma de subverter e questionar sua hierarquia (Ribeiro Júnior, 2016, p. 54, grifo nosso).
} 
Jorente, M. J. V. \& Apocalypse, S. M. | Contribuições do Design da informação para a visibilidade de conteúdos que perpassem a temática LGBT, diversidade de gênero e sexualidade convergidos em

pertinência de arcabouço teórico referente a tais temáticas de modo que possam sustentar novas práticas em âmbito educacional, social e moral.

Neste contexto, considerando que estudos referentes às temáticas já mencionadas têm aflorado nos ambientes universitários, cabe refletir sobre o acesso as produções científicas que perpassam tais questões e quais os meios possíveis para que o compartilhamento desse conteúdo informacional, de extrema relevância social, aconteça de modo eficiente e eficaz.

\section{Filosofia aberta e os Repositórios Institucionais}

O acesso à produção científica na contemporaneidade centralizou diversas discussões referentes ao compartilhamento do conhecimento científico, não somente com a comunidade acadêmica, mas sim com toda sociedade.

Neste contexto, a década de 2000 é marcada pelo movimento a favor do livre acesso à dados científicos, sendo impulsionada pela filosofia aberta com intuito de garantir o acesso à informações científicas e a construção de discussões acerca dos impactos do livre acesso à dados e informações.

[...] à medida que o meio eletrônico, gradual e crescentemente, substitui o meio impresso no contexto

da publicação científica, as mudanças na comunicação aumentam também, provocando crescimento e

diversidade nas interações entre pesquisadores e no desenvolvimento do conhecimento. Isso, por seu

turno, acelera o acesso à informação. De fato, que a tendência principal da comunicação eletrônica

hoje parece ser em direção a uma filosofia aberta (Costa, 2005, p. 177).

Dado o cenário apresentado, surgem às primeiras iniciativas de implantação de repositórios, surgindo então o primeiro repositório eletrônico de dados no ano de 1991, criado pelo laboratório de física nuclear de Los Alamos nos Estados Unidos, caracterizando um grande marco para a efetivação das políticas de livre acesso. (Marcondes \& Sayão, 2009).

Posteriormente a utilização dos repositórios passa a ser difundida por todo o mundo juntamente com a política de livre acesso, neste contexto, a fim de atender às diferentes demandas das instituições que passam a utilizar esta tecnologia, são desenvolvidos diferentes tipos de repositórios.

Os repositórios institucionais têm como finalidade armazenar e disponibilizar a produção científica de instituições, possibilitando o acesso à informação de modo ideal. Como explicitado por Bosso:

Os Repositórios institucionais: englobam a produção científica de determinada instituição, mais comumente institutos de pesquisa e universidades. Hospedam geralmente uma coleção de documentos de pesquisa (pré-prints e pós-prints), embora possam incluir relatórios técnicos, manuscritos, dados, videoclipes e imagens, além de conter dados administrativos de apoio à instituição, como arquivo local de documentação, teses, dissertações, livros e outros (Bosso, 2011, p. 34).

Em um contexto atual, as universidades e agências de fomento são as instituições que sustentam a produção científica no país e a adesão dessas instituições a filosofia aberta ou movimento de livre acesso, garante a comunicação científica no país e o acesso pela sociedade às produções intelectuais. Um dos aspectos a se pontuar, referente ao livre acesso aos dados científicos é a visibilidade tanto das pesquisas quanto dos autores, pois o acesso aberto gratuito impulsiona significativamente à difusão das pesquisas.

A gestão e a visibilidade da informação científica requerem que sejam consideradas as peculiaridades e demandas do complexo ambiente de produção e uso do conhecimento científico, pressupostos que são implícitos na natureza do acesso aberto e dos repositórios institucionais. A maximização do impacto de resultados de pesquisas por meio do aumento do acesso a eles constitui a missão maior do Acesso Aberto, que encontra nos repositórios institucionais uma de suas principais estratégias (Leite, 2009, p. 97).

Os repositórios institucionais configuram o principal meio para que o movimento de acesso 
Jorente, M. J. V. \& Apocalypse, S. M. | Contribuições do Design da informação para a visibilidade de conteúdos que perpassem a temática LGBT, diversidade de gênero e sexualidade convergidos em Repositórios Digitais

aberto seja efetivado, sendo a visibilidade das pesquisas pressupostos do movimento de livre acesso à produção científica, estudos que versem a melhoria dos mecanismos de compartilhamento dos dados científicos possibilitando maior visibilidade desses dados, são de extrema pertinência para o compartilhamento e acesso a informação de modo ideal.

Cabe aludir os impactos do compartilhamento da produção científica. Como aponta Rosa (2009) repercutem tanto para o reconhecimento da instituição a nível nacional e internacional, quanto aos pesquisadores e também para as pesquisas, que alcançam maior visibilidade tanto no âmbito da comunicação científica quanto no acesso da sociedade como um todo ao que é produzido pela academia.

\section{Repositório Institucional da UNESP.}

O Repositório Institucional da UNESP, é desde 28 de fevereiro de 2013, gerido pelo Grupo Gestor da Política do Repositório Institucional Unesp (GRI-UNESP) que atua em conjunto com a Coordenadoria Geral de Bibliotecas (CGB), Núcleo de Educação a Distância, Pró - Reitoria de pós graduação, Fundação e Editora Unesp e a Agência Unesp de Inovação a fim de desenvolver e implementar melhorias no ambiente.

O ambiente converge de maneira significativa a produção científica da instituição com a finalidade de armazenar, preservar e possibilitar acesso às pesquisas desenvolvidas pela universidade. Ao emergir em sua página inicial é possível observar algumas características do ambiente. O repositório oferece uma breve apresentação do Repositório e informações referentes ao auto-arquivamento de teses e dissertações, como na seguinte imagem:

Figura 1: Página inicial do Repositório (Repositório Institucional Unesp, 2019)

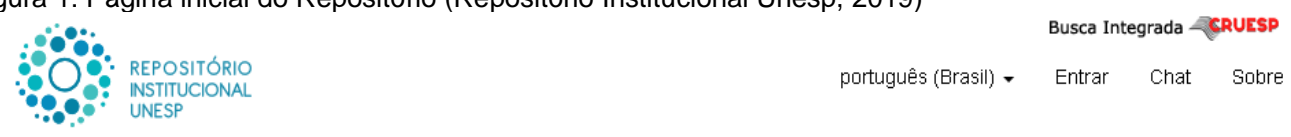

\section{A Repositório Institucional UNESP}

\begin{tabular}{|c|c|c|c|c|}
\hline Pesquisar & \multicolumn{4}{|l|}{ Apresentação } \\
\hline \multicolumn{5}{|c|}{ 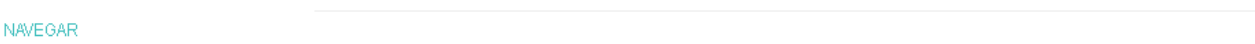 } \\
\hline Em todo o Repositório & \multirow{2}{*}{\multicolumn{4}{|c|}{$\begin{array}{l}\text { O Repositório Institucional UNESP tem por objetivo armazenar, preservar, disseminar e possibilitar o } \\
\text { acesso aberto, como bem público global, à produçăo científica, acadêmica, artística, técnica e administrativa } \\
\text { da Universidade. }\end{array}$}} \\
\hline Tipo de Produção & & & & \\
\hline \multicolumn{5}{|l|}{ Data do documento } \\
\hline Autor & \multicolumn{4}{|c|}{ Autoarquivamento de Dissertações e Teses } \\
\hline \multicolumn{5}{|c|}{ 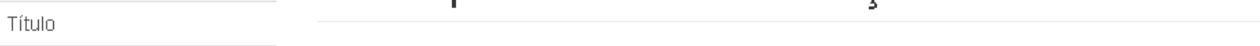 } \\
\hline Palavra-chave & \multicolumn{2}{|c|}{ Para iniciar seu autoarquivamento clique em: } & Entrar & \\
\hline MINHA CONTA & Para mais informaçôes acesse & (3) Informaç & ôes autoarquivamento & \\
\hline \multicolumn{5}{|c|}{ 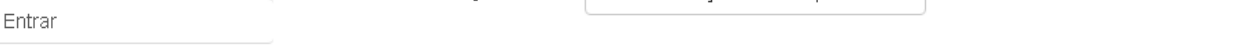 } \\
\hline EXPLORE & \multirow{2}{*}{\multicolumn{4}{|c|}{ Dúvidas }} \\
\hline Tipo & & & & \\
\hline Artigo (59283) & \multirow{2}{*}{\multicolumn{4}{|c|}{$\begin{array}{l}\text { Caso possua dúvidas consulte um bibliotecário (de segunda a sexta das } 09 \mathrm{~h} \text { às } 12 \mathrm{~h} \text {, exceto feriados): } \\
\text { Atendimento online }\end{array}$}} \\
\hline Dissertaçẵo de mestrado & & & & \\
\hline
\end{tabular}

Ainda na página inicial do repositório, como consta na figura 2, ao utilizar a opção "rolar" temos acesso a aos tipos de materiais disponíveis e o tipo de produção convergidos no ambiente dispostos de maneira diferente da barra de tarefas, como na imagem seguinte: 
Jorente, M. J. V. \& Apocalypse, S. M. | Contribuições do Design da informação para a visibilidade de conteúdos que perpassem a temática LGBT, diversidade de gênero e sexualidade convergidos em

Figura 2: Página inicial do Repositório (Repositório Institucional Unesp, 2019)

\begin{tabular}{|c|}
\hline $\begin{array}{l}\text { Trabalho apresentado en everto } \\
\text { (6225) }\end{array}$ \\
\hline ... Ver mais \\
\hline Autor \\
\hline Longo, Elson [UNESP] (992) \\
\hline A.danns, T. (692) \\
\hline Bean, A. (685) \\
\hline ... Ver mais \\
\hline Data de publicaặăo \\
\hline 2010 - 2018 (69703) \\
\hline 2000 - 2009 (38959) \\
\hline 1990 - $1999(6538)$ \\
\hline 1980 - $1989(1507)$ \\
\hline 1970 - 1979(240) \\
\hline 1967 - 1969 (2) \\
\hline diloma \\
\hline por $(72277)$ \\
\hline eng (44639) \\
\hline spa(552) \\
\hline ... Ver mais \\
\hline Agência de fomento \\
\hline $\begin{array}{l}\text { Coordenagăăo de Aperficicoanento de } \\
\text { Pessoald de Nivel Superior (CAPES) } \\
\text { (19683) }\end{array}$ \\
\hline $\begin{array}{l}\text { Fundaçăo de Amparo à Pesquisa do } \\
\text { Estado de Săo Paulo (FAPESP) }\end{array}$ \\
\hline
\end{tabular}
Tipos de materiais

\begin{tabular}{|c|c|c|}
\hline Artigo: 59283 & Dissertaçắo de mestrado: 23856 & Tese de doutorado: 12461 \\
\hline Trabalho de conclusắo de curso: 7753 & Trabalho apresentrado em evento: 6225 & Resuno: 5135 \\
\hline Livro: 457 & Resenha: 368 & Edtorial: 302 \\
\hline Carta: 296 & Podcast: 226 & Pattente: 213 \\
\hline Tese de livre-docência: 148 & Boletin: 78 & Revista: 74 \\
\hline Nota: 35 & Jornal 34 & Relatório: 23 \\
\hline Captulo de livro: 9 & Objetto educacional: 6 & Parttura: 2 \\
\hline Regulamento: 1 & Tese de Doutorado: 1 & \\
\hline
\end{tabular}

Tipo de Produção

Produção administrativa

Produção artística

Produçẫo científica

Produçâao comemorativa - UNESP 40 anos

Nesta segunda página (figura 2) encontra-se localizada a produção técnica e científica da unidade. Observa-se a utilização de cores na apresentação das tipologias e uma espécie de tabela para a separação dos conteúdos. A utilização das cores evidencia os conteúdos disponíveis na parte central da interface.

Ao rolar mais a página são evidenciadas mais informações referentes aos conteúdos convergidos, como na figura 3:

Figura 3: Página inicial do Repositório (Repositório Institucional Unesp, 2019)

\begin{tabular}{|c|}
\hline Palavra-chave \\
\hline human (1807) \\
\hline Brazil (1633) \\
\hline nonhuman (1432) \\
\hline ... Ver mais \\
\hline Pós-graduação \\
\hline Quínica - 19 (891) \\
\hline Medicina Veterinária - FMVZ (853) \\
\hline Engenharia Mecânica - FEG (793) \\
\hline ... Ver mais \\
\hline Campus \\
\hline $\begin{array}{l}\text { Universidade Estadual Paulista } \\
\text { (UNESP), Faculdade de Ciências } \\
\text { Agrárias e Veterinárias, Jaboticabal } \\
\text { (10762) }\end{array}$ \\
\hline $\begin{array}{l}\text { Universidade Estadual Paulista } \\
\text { (UNESP), Faculdade de Medicina, } \\
\text { Botucatu }(8126)\end{array}$ \\
\hline $\begin{array}{l}\text { Universidade Estadual Paulista } \\
\text { (UNESP), Instituto de Biociências, } \\
\text { Botucatu (7313) }\end{array}$ \\
\hline ... Ver mais \\
\hline Estatísticas \\
\hline Estatísticas de uso \\
\hline FEEDS RSS \\
\hline (1) RSS 1.0 \\
\hline ه RSS 2.0 \\
\hline
\end{tabular}

Submissões recentes

Estudo do teor de ácido oxálico em hortaliças e frutos, seu potencial de cristalizaçấo in vitro e
caracterizaçăo morfológica de cristais de oxalato de cálcio Sartarelli, Natálilia Cecilia (Universidade Estadual Paulista (UNESP), 2018) [Dissertaçẩo de mestrado

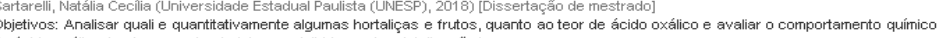

O uso de elementos idiomáticos do berimbau em experimentaçốes composicionais colaborativas Miranda, Fernando de Souza of (Universidade Estadual Paulista (UNESP), 2018) [Dissertaçăo de mestrado] presente trabalho aponta algumas das principais técnicas idiomáticas do berimbau brasileiro, e demonstra como estes elementos foram Subconjunto terminológico da CIPE@ para o cuidado a pessoas portadoras de transtornos mentais Gouvèa, Ana Hilara Mancuso (Universidade Estadual Paulista (UNESP), 2018) [Dissertaçăo de mestrado Introduçấo: O exercício da enfermagem em Saúde Mental no Brasil vem, ao longo dos anos, sofrendo modificaçöes a fiim de atender as Efeito da Terapia Fotodinâmica antimicrobiana (aPDT), com Hipericinaglucamina ativada por LED, na
progressăo e tratamento da doença periodontal induzída ern ratos Macedo, Paula Delello (Universidade Estadual Paulista (IINESP), 2017) [Tese de doutoradi) o objetivo deste trabalho foi avaliar os efeitos da aPDT (antinicrobial photodynamic therapy), com o fotossensibilizador Hipericina-glucamina ( $\mathrm{HY}$-g), ativado por LED âmbar $(34,10 \mathrm{~J} / \mathrm{cm} 2)$, no tratamento e progressăo da doenç̧a .. Modulação do EGFR em complexos cumulus-ó́citos bovinos cultivados in vitro e seus efeitos sobre o
metabolismo, maturacáa e e aquisiçăo da competência oocitária e a transcriçăo gênica das células do cumulus e dos embroes Dall'Acqua, Priscila Chediek sof. (Universidade Estadual Paulista (UNESP), 2018) [Tese de doutorado enduzida por estímulo gonadotrótico. Nós Associaçăo entre complicaçóes perioperatórias e mortalidade, no seguimento de um ano, de pacientes Leme, Fabio Caetano Oliveria की (Universidade Estadual Paulista (UNESP), 2018) [Tese de doutorado] Justificativa e objetivos: a populaçăo mundial está vivendo mais, incorrendo em aumento da incidência de doenças musculoesqueléticas con necessidade cirúrgica, sendo que tratura de fêmur (FF) e coxartrose (CXT) sấo lesöes

Prediçẫo de rotas metabólicas de enzimas utilizando aprendizado de máquina Almeida, Rodrigo de Oliveira (Universidade Estadual Paulista (UNESP), 2018) [Tese de doutorado]
Enzimas săo urna classe de oroteínas resoonsáveis bor catalisar diversos tioos de reacóes

Anais do 9o Congresso Internacional de Design da Informação | CIDI 2019 
Jorente, M. J. V. \& Apocalypse, S. M. | Contribuições do Design da informação para a visibilidade de conteúdos que perpassem a temática LGBT, diversidade de gênero e sexualidade convergidos em Repositórios Digitais

Nesta última parte página inicial do repositório (figura 3), são disponibilizadas na parte central da tela informações referentes às submissões mais recentes no ambiente. Os títulos dos trabalhos são evidenciados por meio da utilização de cores e ao lado na barra de tarefas são apresentadas as principais palavras chave, programas de pós-graduação e unidades da Unesp.

Segue-se na figura 4 a interface de resultados mediante a busca do termo LGBT e as principais características e os recursos disponíveis, como na imagem seguinte:

Figura 4: Resultados de busca do Repositório (Repositório Institucional Unesp, 2019)

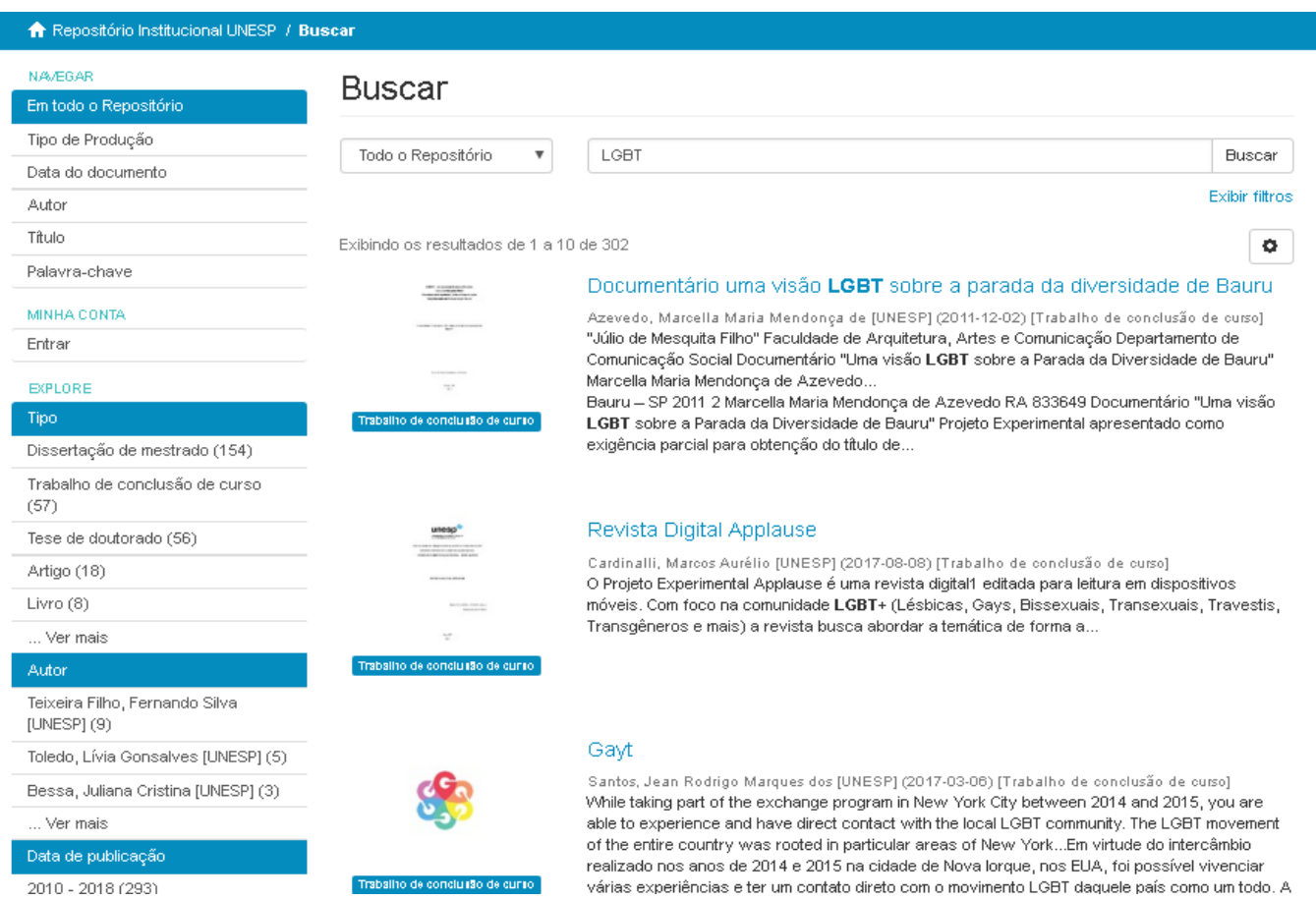

Ao efetivar a busca pelo termo LGBT, torna-se possível identificar como o repositório disponibiliza os conteúdos informacionais relacionados a temática abordada na pesquisa.

Ao clicar sobre o item uma nova página é aberta, qual constam as informações específicas referentes ao item selecionado, como pode ser visualizado na figura seguinte: 
Jorente, M. J. V. \& Apocalypse, S. M. | Contribuições do Design da informação para a visibilidade de conteúdos que perpassem a temática LGBT, diversidade de gênero e sexualidade convergidos em

Figura 5: Página de hospedagem do item selecionado (Repositório Institucional Unesp, 2019)

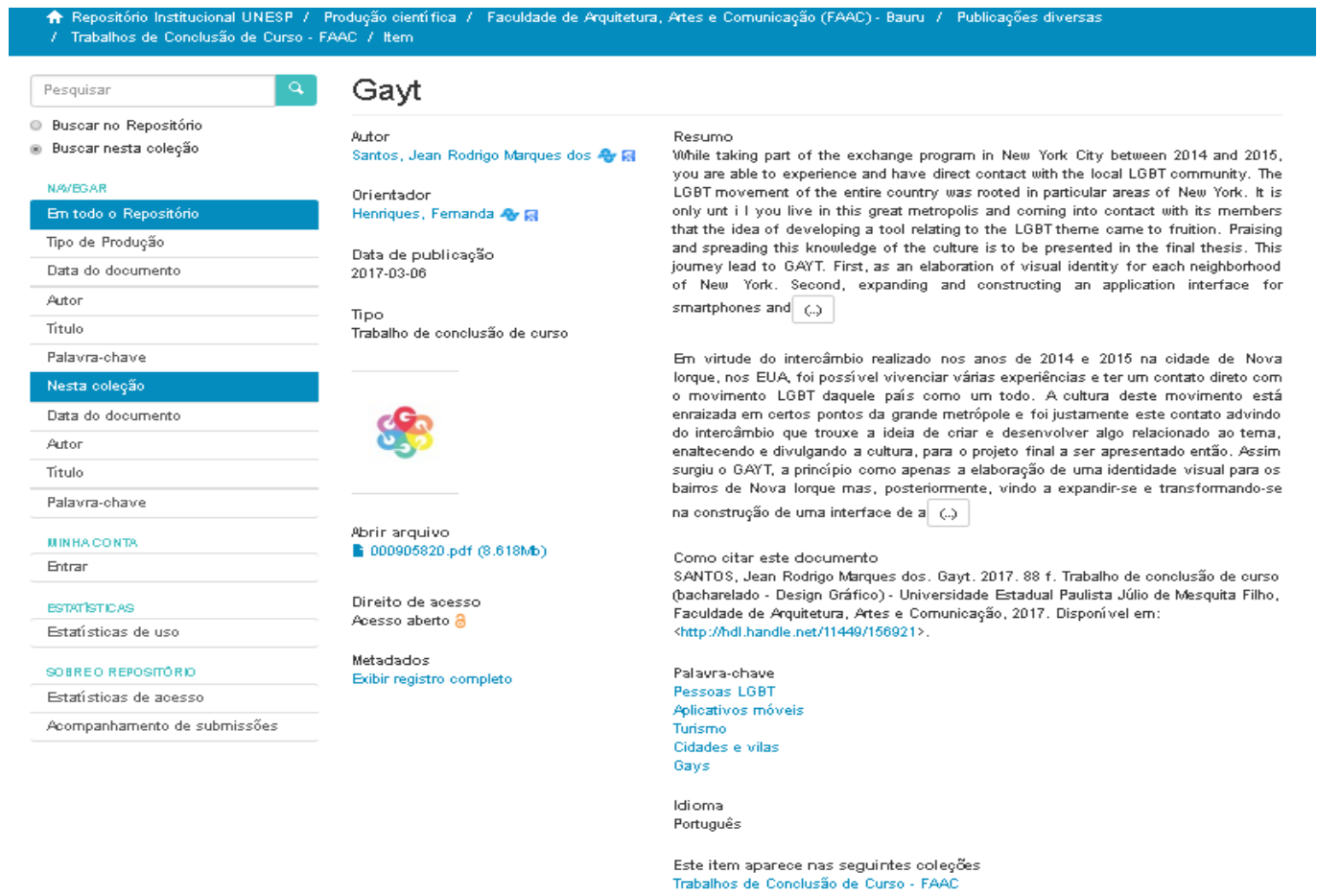

Como consta na figura 5, encontram-se informações específicas do item como o título do trabalho, os autores, a data em que o trabalho foi publicado, a capa em forma de ícone, tipologia do trabalho, opção de download, se encontra-se de livre acesso e um link para os metadados. Ao lado encontram-se o resumo do trabalho, este extraído do próprio trabalho em inglês e português, a referência, palavras-chave, idioma e a qual coleção o trabalho está submetido.

$\mathrm{Na}$ barra de tarefas abaixo do sistema de busca, como na página inicial do repositório encontram-se possibilidades de busca em todo ambiente, seguida das indicações de busca na coleção onde o item se encontra, bem como estatísticas de uso e posteriormente informações sobre o repositório.

\section{Design da Informação}

Considerando o desenvolvimento das TIC e os diferentes ambientes informacionais disponíveis na contemporaneidade, a recuperação, acesso e interação dos indivíduos com tais ambientes, vêm se mostrando como um importante aspecto deste novo panorama informacional a ser estudado.

O DI se apresenta ao campo interdisciplinar da Ciência da informação, podendo ser aplicado em ambientes informacionais já existentes, pois oferece potenciais contribuições para o acesso, compartilhamento e visibilidade de conteúdos informacionais. A interação entre o indivíduo e o ambiente informacional disponível, pode ser melhorada por meio do DI.

O Design da Informação (DI) trata de estudar a percepção e cognição humana para definir e criar modelos visando à melhoria dos trânsitos de conteúdos informacionais em diversos meios e contextos; trata, por outro lado, da representação da informação, de suas estruturas e codificação. Ao atuar nas formas de recepção e de produção de informação, cria meios para facilitar o processo de aquisição da informação e do conhecimento, que se efetivam a partir dos sistemas de comunicação, sejam estes analógicos ou digitais [...] (Jorente, 2015, p. 11). 
Jorente, M. J. V. \& Apocalypse, S. M. | Contribuições do Design da informação para a visibilidade de conteúdos que perpassem a temática LGBT, diversidade de gênero e sexualidade convergidos em Repositórios Digitais

Cabe salientar que uma das principais ocupações do DI, como apresentado por Jorente (2015), é possibilitar a melhoria dos trânsitos de informação, com intuito de auxiliar no processo apreensão da informação disponível em um determinado ambiente.

Para tanto a busca por definir princípios de DI tem permeado as discussões no campo científico dedicado a essa área como os estudos propostos por Pettersson (2012).

De acordo com o autor o DI pode ser aplicado a ambientes informacionais por meio de princípios básicos, possibilitando um sistema adequado para que os indivíduos consigam assimilar informações de modo eficiente e eficaz, atendendo assim suas necessidades informacionais. Assim, Pettersson (2012) estabelece uma série de princípios de DI subdivididos em quatro diretrizes como apresentado no quadro abaixo:

Quadro 1- Princípios de Design da Informação (Adaptado: Pettersson, 2012, p. 171, tradução nossa)

\begin{tabular}{|l|l|}
\hline Princípios funcionais & Princípios estéticos \\
\hline $\begin{array}{l}\text { Definindo o problema } \\
\text { Fornecendo estrutura } \\
\text { Fornecendo clareza }\end{array}$ & $\begin{array}{l}\text { Harmonia } \\
\text { Proporção estética }\end{array}$ \\
$\begin{array}{l}\text { Proporcionando simplicidade } \\
\text { Fornecendo ênfase }\end{array}$ & \\
Fornecendo unidade & \\
\hline Princípios administrativos & Princípios cognitivos \\
\hline Acesso à informação & Facilitando a atenção \\
Custos da informação & Facilitando a percepção \\
Ética da informação & Facilitando o processamento \\
Assegurar a qualidade & Facilitando a memória \\
\hline
\end{tabular}

A partir dos princípios de DI elencados, torna-se possível avaliar ambientes informacionais e pontuar se o mesmo encontra-se em conformidade com um espaço que permite a apreensão da informação disponível.

\section{Resultados encontrados}

Após resgatar os princípios de DI propostos por Pettersson (2012), torna-se possível efetivar uma análise prática da aplicação dos princípios no ambiente em questão.

Mediante a análise dos princípios funcionais, considerando a primeira diretriz que corresponde a um diagnóstico geral do ambiente e os objetivos pretendidos, deve-se considerar a finalidade dos Repositórios Institucionais, suas possibilidades referentes ao compartilhamento de dados e informações. Neste caso, como apresentado nas políticas do 
repositório, sua principal finalidade consiste em compartilhar a toda comunidade a produção diversa constituída no âmbito da universidade.

A segunda diretriz corresponde a estrutura da informação apresentada, observa-se que as informações estão dispostas no ambiente de modo estruturado, sendo utilizado uma hierarquia de cores e tamanhos de fontes, contudo o principal conteúdo apresentado na página inicial não corresponde à produção técnica e científica constituída no âmbito da universidade, mas sim à apresentação do ambiente, informações referentes ao auto-arquivamento e meios de contato.

A terceira diretriz "Fornecer clareza" pode ser identificada por meio de recursos como a utilização de cores, fontes e disposição dos conteúdos no ambiente. Observa-se que é presente no ambiente a utilização de cores para evidenciar e estabelecer uma hierarquia entre os conteúdos. As variações de tamanhos da fonte também evidenciam a hierarquia dos conteúdos.

A diretriz "fornecer simplicidade" implica a garantia de que os conteúdos possam ser apreendidos de maneira simples, ou seja, devem estar de fácil entendimento a quem venha acessá-la. A página inicial do repositório embora apresente hierarquias na apresentação dos conteúdos que podem ser visualizados através das cores e do tamanho das fontes, possui uma grande quantidade de informações heterogêneas concentradas na página de apresentação. Como pode ser visualizado na figura 1, em um único espaço localiza-se a apresentação do ambiente, informações referentes ao autoarquivamento e informações de contato. Essa característica coloca em segundo plano a apresentação do conteúdo produzido no âmbito da universidade, não contribuindo para o alcance dos objetivos do repositório.

Ao considerar a diretriz "fornecendo ênfase" observa-se que recursos são utilizados para possibilitar o enfoque em determinados conteúdos. A utilização das cores em determinados campos os coloca em evidência. Observa-se também que o tamanho das fontes presentes nos enunciados auxilia na visibilidade do que é apresentado. Ao efetivar a busca pelo termo LGBT, observa-se que dentre os itens selecionados, o trabalho que apresenta na capa as cores da bandeira que representa a comunidade LGBT fica em evidência em comparação aos demais itens. A presença de cores diferenciadas, e neste caso que possuem um significado e representam a comunidade em questão, possibilita uma maior visibilidade do item.

Por fim a última diretriz deste grupo a diretriz "fornecendo unidade" busca pontuar a importância de que todo o ambiente possuía uma coerência. Deste modo, identifica-se que a página inicial do repositório apresenta seus conteúdos de forma coerente. A utilização de recursos para dar ênfase, como as cores e os diferentes tamanhos de fontes seguem uma linearidade. Contudo as informações contidas na página inicial não se apresentam de acordo com o propósito do repositório correspondem a mensagens distintas centralizadas em um único espaço podendo confundir sujeito que venha navegar no ambiente.

Ao pontuar os princípios estéticos e suas contribuições quanto a apresentação de conteúdos de maneira atrativa e agradável, a primeira diretriz deste princípio, a "harmonia" trata de considerar a necessidade de que as informações estejam harmonicamente organizadas no ambiente, deste modo a relação harmônica dos conteúdos podem contribuir para a eficiência na comunicação de conteúdos. Ao analisar a interface do repositório, considerando este princípio, identifica-se que há um grande excesso de informações heterogêneas concentradas na página inicial. A página de resultados de busca e a página do item selecionado apresentam harmonia na apresentação dos conteúdos.

Ainda no subconjunto de diretrizes dos princípios estéticos, a proporção estética configurase como parte dos recursos de Design que permitem criar um ambiente agradável, deste modo, o ambiente como um todo deve apresentar proporção, unidade e harmonia não somente na apresentação dos conteúdos, mas também, na hierarquia de cores, ícones, figuras, entre outros. As informações na página inicial e de resultados são dívidas em duas partes, sendo a central conteúdos gerais e resultados de busca e uma barra de tarefas no lado esquerdo. Já a página em que se localiza o item é dividida em três partes, sendo elas a barra de tarefas à esquerda seguida de informações referentes aos produtores do trabalho, tipologia, capa, entre outros e a terceira o resumo do trabalho, referência e palavras-chave. Observa-se que o 
ambiente em questão se apresenta esteticamente harmonioso quanto as suas cores, contudo como já pontuado, o excesso de conteúdos heterogêneos prejudica tanto a harmonia quanto a proporção estética.

Como último grupo de princípios de DI, encontram-se os princípios cognitivos, quais tratam da percepção do sujeito com o ambiente e conteúdos apresentados. Sendo uma das principais características do DI a adequação de conteúdos e ambientes informacionais considerando as necessidades dos indivíduos que venham acessar tais informações, os princípios cognitivos implicam bons resultados da interação, comunicação e apreensão de conteúdos entre sujeito e ambiente informacional.

Deste modo, o primeiro princípio dessa diretriz, facilitar a atenção concerne em evitar a dispersão dos sujeitos mediante as informações apresentadas, possibilitando uma boa apreensão dos conteúdos. Identifica-se que embora a interface do repositório utilize cores, hierarquias e textos, a heterogeneidade das informações dificultam a atenção e a encontrabilidade da informação.

A diretriz "facilitando a percepção", que configura uma boa percepção do ambiente e dos recursos e conteúdos oferecidos, de modo a facilitar a encontrabilidade dos conteúdos disponíveis também é fundamental para a eficiência e eficácia de um ambiente. Constata-se mediante a imersão no ambiente que a hierarquia existente e o jogo de cores auxiliam na percepção do ambiente, contudo a falta de informações com campos específicos dificulta a percepção dos conteúdos oferecidos. Nesse sentido torna-se necessário um grande esforço para compreender a dinâmica do ambiente e a disposição dos conteúdos. A página de resultados de pesquisa permite uma boa assimilação dos conteúdos recuperados, todavia o item que apresentou cores correspondentes às da bandeira LGBT facilitou a identificação do item quanto trabalho relacionado a temática buscada.

A diretriz "facilitando o processamento mental" alinha-se a diretriz anterior. A não existência ordem na disposição dos conteúdos, mantendo os aglomerados em uma única página, como as informações dispostas na página inicial, dificultam o processamento mental, além de que, informações relevantes como o sistema de buscas e os materiais convergidos nos ambientes necessitam estar em evidência, considerando o objetivo do repositório. As demais páginas analisadas oferecem boas condições para o processamento das mensagens.

Por fim a diretriz facilitando a memória, em convergência com as anteriores citadas, trata da possibilidade de memorização da dinâmica do ambiente, desse modo, observou-se que a falta de recursos iconográficos e imagéticos dificulta a memorização dos conteúdos, bem como, a falta de uma organização mais homogênea na página inicial, não concentrando muitos conteúdos informacionais.

As páginas de recuperação dos itens e de acesso detalhado ao item selecionado apresentam boa facilidade em memorizar a dinâmica organizacional do ambiente, contudo a presença de cores e ou ícones que possibilitem a identificação mais rápida dos conteúdos podem auxiliar na memorização.

Ao aludir os princípios de DI propostos por Pettersson (2012) identificou-se suas preponderantes contribuições para o compartilhamento e visibilidade de trabalhos convergidos em diversos ambientes Web. Quanto ao aspecto formal, identificou-se na página do repositório a presença de grande quantidade de conteúdos distintos o que dificulta os processos mentais, intuitivos, ou de memorização, bem como a encontrabilidade e usabilidade dos recursos disponíveis.

Como um dos principais resultados da atual pesquisa identificou-se a necessidade de um modelo para construção desses ambientes, com base nos princípios de DI. Nesse modelo pode prever-se o uso de recursos de DI, como a utilização de ícones, cores, fontes entre outros, que possibilitam adequar a informação, referente às produções relativas à temática LGBT, diversidade de gênero e sexualidade aos sujeitos informacionais. Por exemplo, o uso de ícones ou cores representativas como as identificadas na bandeira que representa a comunidade, contribuindo para que o item documental seja evidenciado. Este recurso possibilita, portanto, a 
Jorente, M. J. V. \& Apocalypse, S. M. | Contribuições do Design da informação para a visibilidade de conteúdos que perpassem a temática LGBT, diversidade de gênero e sexualidade convergidos em

sua identificação de modo mais rápido, bem como a sua memorização e o processamento cognitivo envolvidos no acesso.

\section{Considerações}

Estudos no campo da Ciência da Informação e disciplinas correlatas que versam a criação dos repositórios, bem como as contribuições do DI e suas bases conceituais e aplicação prática em ambientes informacionais digitais, com foco em temáticas que possuem pouca visibilidade são necessárias.

Embora trabalhos referentes à temática LGBT, diversidade de gênero e sexualidade apresentem um crescimento nestes ambientes, a quantidade de trabalhos convergidos corresponde um número muito baixo se comparado com o total de itens convergidos nos repositórios. É pertinente pontuar que a abordagem dessas temáticas em ambientes acadêmicos, configura um panorama contemporâneo, sendo um fenômeno bastante atual.

Cabe salientar que o DI oferece subsídios para que os conteúdos convergidos no ambiente sejam evidenciados ou não, deste modo, o profissional atuante neste campo deve compreender as demandas sociais informacionais e adequar o ambiente de acordo com as necessidades, bem como, identificar que determinadas temáticas possuem demandas diferenciadas e carências e serem supridas. Nesse sentido, são necessários esforços para que meios sejam encontrados e problemas sejam solucionados.

Pontua-se, assim, a importância de que profissionais da informação desenvolvam e aprimorem competências em DI, considerando que este campo do conhecimento concerne de modo pontual a atuação dos profissionais da informação enquanto mediadores de informações.

Por meio da análise da aplicação prática do DI no repositório, tornou-se possível identificar as contribuições desse campo do conhecimento para a visualização de dados convergidos no meio digital e, em específico, para a visibilidade de pesquisas relacionadas à temática LGBT, diversidade de gênero e sexualidade em repositórios.

A característica dinâmica do DI torna possível identificar os princípios adequados, a sua aplicação em repositórios e configura um campo de estudo para a construção eficiente e eficaz desses espaços, de modo que venham a cumprir sua principal função de compartilhamento de conhecimentos e contribuir para eliminação da ignorância sobre a diversidade sexual e de gênero.

\section{Agradecimento}

Agradecimentos especiais à Fundação de Amparo à Pesquisa do Estado de São Paulo (FAPESP), processo número 2017/23458-3, pelo apoio financeiro ao projeto de pesquisa. As opiniões, hipóteses e conclusões ou recomendações expressas neste material são de responsabilidade do(s) autor(es) e não necessariamente refletem a visão da FAPESP.

\section{Referências}

Boso, A. K. (2011). Repositórios de instituições federais de ensino superior e suas políticas: análise sob o aspecto das fontes informacionais. Dissertação de mestrado, Universidade Federal de Santa Catarina, Programa de Pós-Graduação em Ciência da Informação, Florianópolis, SC, Brasil. Disponível em: https://repositorio.ufsc.br/bitstream/handle/123456789/95776/296890.pdf?sequence=1 \&isAllowed $=y$ 
Jorente, M. J. V. \& Apocalypse, S. M. | Contribuições do Design da informação para a visibilidade de conteúdos que perpassem a temática LGBT, diversidade de gênero e sexualidade convergidos em Repositórios Digitais

Brasil. (2013). Relatório sobre violência homofóbica no Brasil: ano de 2012. Brasília: Secretaria de Direitos Humanos da Presidência da República. Recuperado em 10 maio, 2019, de http://bibspi.planejamento.gov.br/bitstream/handle/iditem/571/RELATORIO\%20VIOLEN CIA\%20HOMOFOBICA\%20ANO\%202012.pdf?sequence=1\&isAllowed=y

Butler, J. (2014). Regulações de gênero. Cadernos Pagu. 42, 249-274. Recuperado em 10 maio, 2018, de http://www.scielo.br/pdf/cpa/n42/0104-8333-cpa-42-00249.pdf

Costa, S. M. S. A. (2005). Comunicação científica nos dias atuais: impactos de uma "Filosofia Aberta" In: C.H. Marcondes, H. Kuramoto, L. B. Toutain '\&' L. Sayão (orgs). Bibliotecas digitais: saberes e práticas. Salvador/Brasília: UFBA/IBICT.

Grupo Gay Da Bahia. (2017). Pessoas LGBT mortas no Brasil: relatório 2017. Recuperado em 10 maio, 2019, de https://homofobiamata.files.wordpress.com/2017/12/relatorio2081.pdf

Jorente, M. J. V. (2015). Tecnologia e design da informação: interdisciplinaridades e novas perspectivas para a Ciência da Informação. Bauru, São Paulo: Canal 6.

Leite, F. C. L. (2009). Como gerenciar e ampliar a visibilidade da informação científica brasileira Repositórios Institucionais de Acesso Aberto. 2. ed. Brasília: IBICT. Recuperado em 08 junho, 2018, de http://livroaberto.ibict.br/bitstream/1/775/4/Como gerenciar e ampliar a visibilidade da informação científica brasileira.pdf

Leite, F. et al. (2012). Repositórios institucionais: boas práticas para a construção de repositórios institucionais da produção científica. Brasília: IBICT.

Marcondes C. H; Sayão L. F. (2009). Repositórios institucionais e livre acesso In. L. Sayão, L. B. Toutain, F. G. Rosa '\&' C. H. Marcondes (Org.). Implantação e gestão de repositórios institucionais: políticas, memória, livre acesso e preservação. Bahia: Edufba.

Pettersson, R. (2012). It Depends: Information Design - Principles and Guidelines, 4th Edition. Institute for Infology. Retrieved may, 16, 2019, from http://www.iiid.eu/PublicLibrary/PetterssonRune-ID-It-Depends.pdf

Planella Ribera, J. (2017). Corpo, cultura e educação. Tradução de Maria José Vicentini Jorente; Natalia Nakano; Lais Alpi Landim. São Paulo: Cultura Acadêmica.

Repositório Intitucional Unesp. (2016). Grupo Gestor do Repositório Institucional

UNESP. Regulamento Interno do Repositório Institucional UNESP. Universidade Estadual Paulista (UNESP). Recuperado em 10 maio, 2019, de http://hdl.handle.net/11449/144653.

Repositório Intitucional Unesp. (2019). Perguntas frequentes. Recuperado em 10 maio, 2019, de https://repositorio.unesp.br/page/about

Rosa F. G. (2009). Implantação do repositório institucional da Universidade Federal da Bahia: uma política de acesso à produção científica In. L. Sayão, L. B. Toutain, F. G. Rosa '\&' C. H. Marcondes (Org.). Implantação e gestão de repositórios institucionais: políticas, memória, livre acesso e preservação. Bahia: Edufba.

\section{Sobre o(a/s) autor(a/es)}

Maria José Vicentini Jorente, Professora Dra, Unesp, Brasil <maria.jose-vicentinijorente@unesp.br.com>

Simão Marcos Apocalypse, Unesp, Brasil

<simao.apocalypse@gmail.com> 